\title{
ChemComm
}

Cite this: Chem. Commun., 2013, 49, 8985

Received 17th July 2013, Accepted 5th August 2013

DOI: $10.1039 / c 3 c c 45416 a$

\section{Revealing and accelerating slow electron transport in amorphous molybdenum sulphide particles for hydrogen evolution reaction $†$}

\author{
Heron Vrubel, ${ }^{\mathrm{a}}$ Thomas Moehl, $^{\mathrm{b}}$ Michael Grätzel ${ }^{\mathrm{b}}$ and Xile Hu*a
}

www.rsc.org/chemcomm

\begin{abstract}
Electrochemical impedance spectroscopy is used to identify a slow electron transport process in hydrogen evolution catalysed by amorphous molybdenum sulphides on glassy carbon. A new chemical synthesis leads to an amorphous molybdenum sulfide catalyst with a higher electronic conductivity.
\end{abstract}

The hydrogen evolution reaction (HER, eqn (1)) has drawn much attention because it is an essential component of water splitting, a process that enables the storage of solar and wind energy in the form of chemical fuels. ${ }^{1}$

$$
2 \mathrm{H}^{+}+\mathrm{e}^{-} \rightleftharpoons \mathrm{H}_{2}
$$

While electron transport in the catalyst is a separate process from charge transfer reactions, it affects the global activity of a catalyst. As described below, a slow electron transport leads to a higher apparent Tafel slope than that dictated by the mechanism of charge transfer reactions. This is detrimental to the application of a catalyst in a practical system, where a non-negligible overpotential is always applied to ensure a useful reaction rate. For metallic HER catalysts, electron transport is normally rapid, as metallic catalysts are good electronic conductors. For electrodes made of an assembly of nanoparticles, especially non-metallic nanoparticles, electron transport can become a bottleneck in HER. This seems to be the case with molybdenum sulphides.

Recently, various molybdenum sulphide materials have been identified as a promising class of non-precious catalysts for HER under acidic conditions. ${ }^{2-12}$ The Tafel slopes of these catalysts differ significantly, ranging from 40 to $200 \mathrm{mV}$ per decade. As $\mathrm{MoS}_{2}$ is an intrinsic semiconductor with a marked anisotropic behavior in conductivity, slow electron transport is likely the origin of the higher

\footnotetext{
${ }^{a}$ Laboratory of Inorganic Synthesis and Catalysis, Institute of Chemical Sciences and Engineering, Ecole Polytechnique Fédérale de Lausanne (EPFL), EPFL-ISIC-LSCI, BCH 3305, Lausanne, CH 1015, Switzerland. E-mail: xile.hu@epfl.ch; Fax: +41 216939305; Tel: +41 216939781

${ }^{b}$ Laboratory of Photonics and Interfaces, Institute of Chemical Sciences and Engineering, Ecole Polytechnique Fédérale de Lausanne (EPFL), Lausanne, CH 1015, Switzerland

$\dagger$ Electronic supplementary information (ESI) available: Experiemental details and additional graphs. See DOI: 10.1039/c3cc45416a
}

apparent Tafel slopes in certain molybdenum sulphide catalysts. In agreement with this hypothesis, Dai and co-workers found a Tafel slope of $41 \mathrm{mV}$ per decade for $\mathrm{MoS}_{2}$ nanoparticles on a graphene oxide sheet; without coupling to graphene, the Tafel slope of $\mathrm{MoS}_{2}$ was $94 \mathrm{mV}$ per decade. ${ }^{9}$ They proposed that the electronic communication between $\mathrm{MoS}_{2}$ and graphene facilitated electron transport and led to a lower Tafel slope.

While electron transport is an integral component of HER, it is hard to be directly identified in such a reaction that involves multiple proton-coupled electron transfers. Tafel analysis may provide a hint of a slow electron transfer; however, a change of the Tafel slope can originate from a change of the reaction mechanism. Furthermore, Tafel analysis is complicated by the different ways iR-drops are corrected, some of which include correction on slow electron transport. Herein, we use electrochemical impedance spectroscopy to reveal, for the first time, a slow electron transport process in HER catalyzed by molybdenum sulphides. Furthermore, we show that chemical activation of amorphous molybdenum sulphide particles enhances electron transport, resulting in a better catalyst.

We reported earlier that amorphous $\mathrm{MoS}_{3}$ particles were good precatalysts for HER. ${ }^{8}$ XPS and electrochemical data showed that the $\mathrm{MoS}_{3}$ particles were electrochemically activated prior to HER. The activation is a reductive process, and the active species $\operatorname{MoS}_{x}$ have a composition similar to $\mathrm{MoS}_{2}$, but are chemically distinct from $\mathrm{MoS}_{2}$ as two different sulphide ions are observed by XPS. The Tafel slopes are $40-60 \mathrm{mV}$ per decade, depending on substrate and catalyst loading. The variance in the apparent Tafel slope of the same material suggests that electron transport in some samples of $\operatorname{MoS}_{x}$ particles might be slow enough to hinder HER; thus, these $\operatorname{MoS}_{x}$ particles are well suited for the study of electron transport in HER.

Fig. 1 shows the stable polarization curves of glassy carbon electrodes modified with $\mathrm{MoS}_{3}$ particles. The activity increases with an increased loading of catalysts. The Tafel slopes vary with loading as well: a higher Tafel slope is observed for an electrode with a high loading (Table 1). For example, the Tafel slope is $47 \mathrm{mV}$ per decade at a loading of $28.2 \mu \mathrm{g} \mathrm{cm} \mathrm{cm}^{-2}$, and $62 \mathrm{mV}$ per decade at a loading of $282 \mu \mathrm{g} \mathrm{cm}^{-2}$. The increase in the Tafel slope compromises the catalytic activity of an electrode with a higher catalyst loading, in other words, the scalability of the system. 


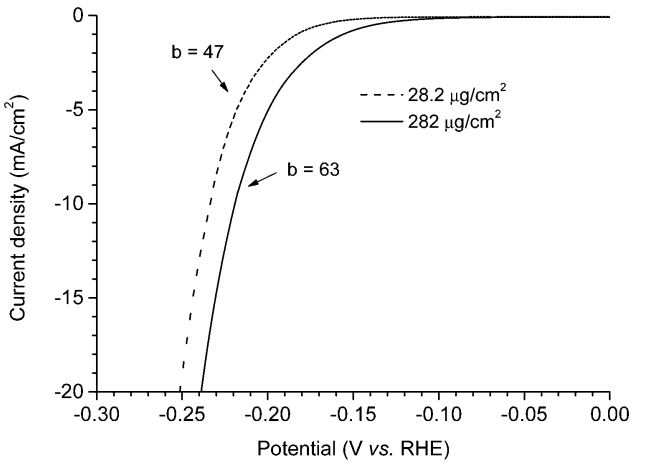

Fig. 1 Polarization curves (10th) of glassy carbon electrodes modified with two different loadings of $\mathrm{MoS}_{3}$. Scan rate $=1 \mathrm{mV} \mathrm{s}^{-1} ; 1 \mathrm{M} \mathrm{H}_{2} \mathrm{SO}_{4}$.

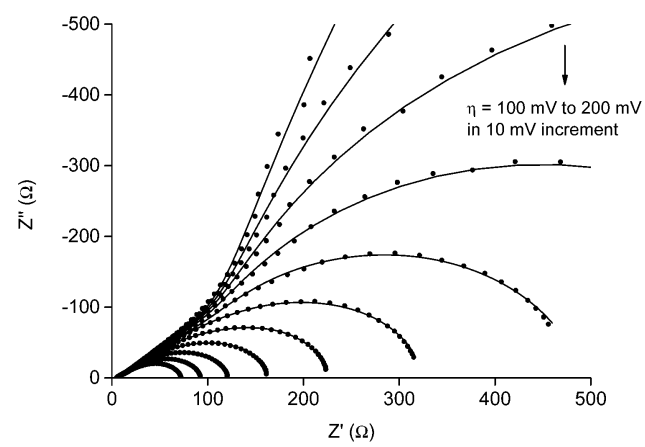

Fig. 2 The Nyquist plot and fitting for the impedance response of the $\mathrm{MoS}_{3}$ modified electrode at a loading of $282 \mu \mathrm{g} \mathrm{cm}^{-2}$.

Electrochemical impedance spectroscopy was applied to characterize the HER reaction catalyzed by $\mathrm{MoS}_{3}$-modified electrodes. Fig. 2 and Fig. S1 (ESI + ) show the Nyquist plots of two electrodes, one with a loading of $28.2 \mu \mathrm{g} \mathrm{cm}^{-2}$ and the other with a loading of $282 \mu \mathrm{g} \mathrm{cm}$. These two loadings are chosen to represent the low and high loading scenarios. The difference of the two plots is significant. At a low loading of catalyst (Fig. S1, ESI + ), the Nyquist plot contains two semicircles and a small $45^{\circ}$ feature at high frequencies. This feature is more visible for the samples with higher loading of the catalyst, as shown in Fig. 2. The data for both samples can be fit with an equivalent electric circuit as in Fig. 3. The semicircle at lower frequencies is potential-dependent and represents the charge transfer process; thus, $R_{\text {ct }}$ is the charge transfer resistance. The semicircle at higher frequencies represents a time constant that is largely potentialindependent $\left(R_{2}\right.$ and $\left.\mathrm{CPE}_{2}\right)$ and is most probably related to the contact between the glassy carbon electrode and the catalyst.

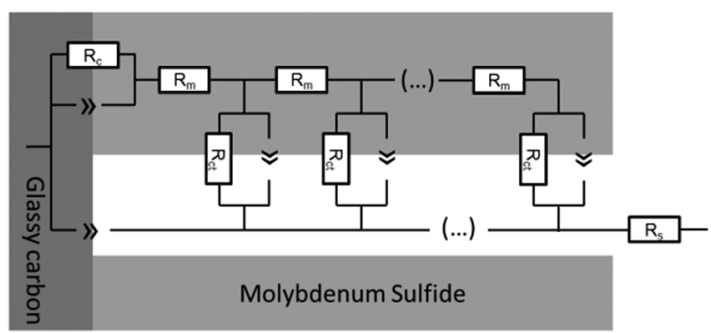

Fig. 3 The equivalent circuit for the impedance data using a transmission line model; $R_{c}$ represents the contact resistance of the electrode with the film.
The $45^{\circ}$ line feature observed in the Nyquist plots is associated with slow electron transport in the catalyst layer. Previously the transmission line model was applied to model the porous materials with intermediate resistivity, for example, $\mathrm{TiO}_{2}$ films in dye sensitized solar cells. ${ }^{13-15}$ We adapted the transmission line model for HER catalyzed by $\operatorname{MoS}_{x}$ particles on glassy carbon (Fig. 3). The layer structure is accounted for by repeating units of $R_{\mathrm{m}}$ in series with $R_{\mathrm{ct}}$, where $R_{\mathrm{m}}$ represents a non-negligible electronic resistance of $\operatorname{MoS}_{x}$. Fig. 2 and Fig. S1 (ESI†) show that the impedance data can be fit with this model. With a 10-fold increase in the loading of catalyst, the recombination resistance and the associated capacitance decrease and increase similarly, not by the expected factor of 10 , but by a factor of 5 to 6 (Fig. 4). The associated time constants $\left(\tau_{\mathrm{ct}}=R_{\mathrm{ct}} \times C_{\mathrm{ct}}\right)$ regarding the recombination are nearly identical for the high and low loadings, showing no change in the catalytic activity of material. The transport time $\left(\tau_{\mathrm{m}}=R_{\mathrm{m}} \times C_{\mathrm{ct}}\right)$ in the higher loading sample is about 10 times of that of the lower loading sample, showing the increased pathlength in the former. Thus, the impedance data confirm that electron transport in $\mathrm{MoS}_{x}$ particles is slow at a high loading, limiting the catalysis. The success of the transmission line model is also in agreement with the porous nature of the catalyst layer, which was previously revealed by SEM. ${ }^{8}$

The plot of $\log R_{\mathrm{ct}} v s$. overpotential gives the Tafel slope from impedance data. Fig. S2 (ESI†) shows such plots for the two loadings. A slope of $37 \mathrm{mV}$ per decade was found at a loading of $28.2 \mu \mathrm{g} \mathrm{cm} \mathrm{cm}^{-2}$; that of $38 \mathrm{mV}$ per decade was found at a loading of $282 \mu \mathrm{g} \mathrm{cm} \mathrm{cm}^{-2}$ (Table 1). Tafel slopes obtained in this way reflect purely the charge transfer kinetics, in contrast to Tafel slopes obtained from voltammetry data which may include contributions from catalyst resistance. The charge transfer Tafel slope of $38 \mathrm{mV}$ per decade suggests that the surface coverage of hydrogen is less than $10 \%$, and the HER proceeds via a fast discharge reaction (Volmer step) and a ratedetermining ion + atom reaction (Heyrovsky step). ${ }^{16}$
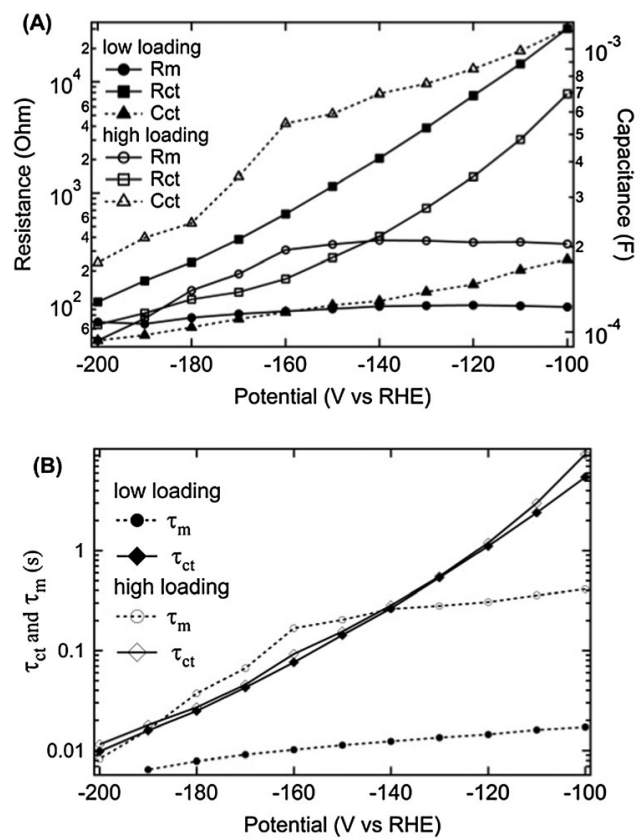

Fig. 4 Plots of the extracted parameters for $R_{\mathrm{ct}}, R_{\mathrm{m}}$ and $\mathrm{C}_{\mathrm{ct}}$ for the $\mathrm{MoS}_{3^{-}}$ modified electrode (A) and the determined lifetime for the processes (B). 
Table 1 Tafel slopes for different catalysts ${ }^{a}$

\begin{tabular}{lcll}
\hline & $\begin{array}{l}\text { Loading } \\
\left(\mu \mathrm{g} \mathrm{cm} \mathrm{cm}^{-2}\right)\end{array}$ & $\begin{array}{l}\text { Slope from } \\
\text { polarization curve } \\
(\mathrm{mV} \text { per decade })\end{array}$ & $\begin{array}{l}\text { Slope from } \\
\text { impedance data } \\
(\mathrm{mV} \text { per decade })\end{array}$ \\
\hline $\mathrm{MoS}_{3}$ & 28.2 & 47 & 37 \\
$\mathrm{MoS}_{3}$ & 282 & 62 & 38 \\
$\mathrm{MoS}_{x}$-CR & 25.2 & 36 & 35 \\
$\mathrm{MoS}_{x}$-CR & 252 & 35 & 38 \\
$\mathrm{MoS}_{3}-\mathrm{V}^{a}$ & 145 & 36 & 37 \\
${ }^{a}$ From a limited region where the Tafel relation is fulfilled.
\end{tabular}

We next tried to accelerate electron transport in $\operatorname{MoS}_{x}$ particles. Previously $\mathrm{MoS}_{3}$ particles were electrochemically reduced to form the active $\operatorname{MoS}_{x}$ particles. ${ }^{8}$ We decided to chemically reduce $\mathrm{MoS}_{3}$ to $\mathrm{MoS}_{x}$, hoping that a different synthetic procedure can bring about a different conductance. Reduction of $\left[\mathrm{MoS}_{4}\right]^{2-}$ with $\mathrm{NaBH}_{4}$ yielded an amorphous molybdenum sulphide species $\left(\operatorname{MoS}_{x}\right.$-CR; CR stands for chemical reduction) that has similar XPS spectra to $\mathrm{MoS}_{x}$ particles generated by electrochemical reduction of $\mathrm{MoS}_{3}$ (Fig. S3, ESI + ).

Fig. 5 shows the stable polarization curves of glassy carbon electrodes modified with $\operatorname{MoS}_{x}-\mathrm{CR}$. The apparent Tafel slopes obtained from the polarization curves are about $36 \mathrm{mV}$ per decade at both low $\left(25.2 \mu \mathrm{g} \mathrm{cm} \mathrm{cm}^{-2}\right)$ and high $\left(252 \mu \mathrm{g} \mathrm{cm} \mathrm{cm}^{-2}\right)$ loadings (Table 1$)$. Nyquist plots of the impedance data for the catalysts at these two loadings (Fig. 6 for the high loading and Fig. S4 (ESI + ) for the low loading) are similar and can be fit with the equivalent circuit shown in Fig. 3. The electron transport in $\mathrm{MoS}_{x}$-CR particles is faster compared to the $\mathrm{MoS}_{3}$ samples. The chemical reduction, therefore,

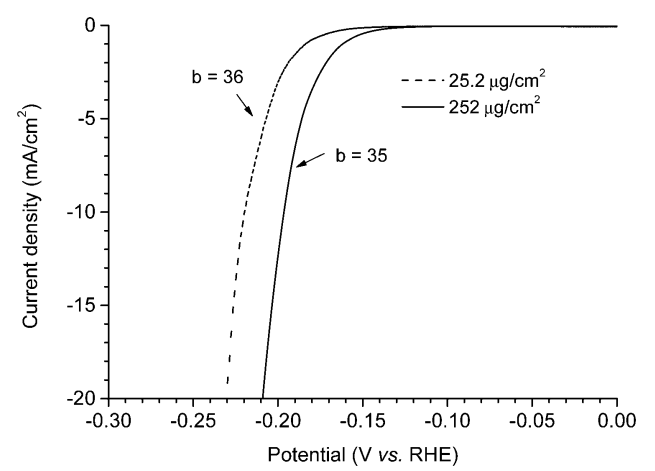

Fig. 5 Polarization curves (10th) of glassy carbon electrodes modified with two different loadings of $\mathrm{MoS}_{x}$ produced by reduction using $\mathrm{NaBH}_{4}$. Scan rate = $1 \mathrm{mV} \mathrm{s}^{-1} ; 1 \mathrm{M} \mathrm{H}_{2} \mathrm{SO}_{4}$.

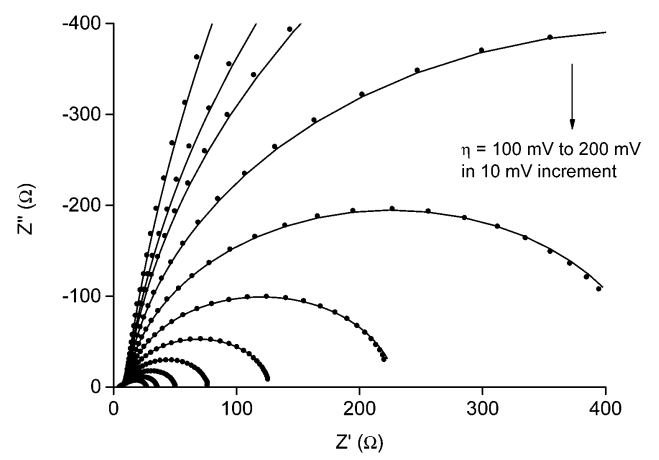

Fig. 6 The Nyquist plot and fitting for the impedance response of a $\mathrm{MoS}_{x}-\mathrm{CR}$ modified electrode at a loading of $252 \mu \mathrm{g} \mathrm{cm}{ }^{-2}$. produces a more conductive $\operatorname{MoS}_{x}$ catalyst than electrochemical reduction. On the other hand, it can be observed from the values of the time constants for the charge transfer reaction that the activity of $\mathrm{MoS}_{3}$ and $\mathrm{MoS}_{x}$-CR towards HER is similar (Fig. S5, ESI $\dagger$ ). Thus, going from $\mathrm{MoS}_{3}$ to $\mathrm{MoS}_{x}-\mathrm{CR}$, the catalytic activity is maintained while the conductivity of the material is increased.

It was reported that hybrid composites of molybdenum sulphides with graphene and mesoporous carbon showed enhanced HER activity than molybdenum sulphides alone. ${ }^{9,11}$ We suspected that the higher activity of hybrid materials is partially due to enhanced electron transport. To corroborate this hypothesis, we prepared an amorphous $\mathrm{MoS}_{3} /$ Vulcan $^{\circledR} \mathrm{C}$ (Vulcan ${ }^{\circledR} \mathrm{C}$ is a type of carbon black particles) hybrid and measured its HER activity. At a loading of about $145 \mu \mathrm{g} \mathrm{cm}{ }^{-2}$, the Tafel slope from the polarization curve is $36 \mathrm{mV}$ per decade (Fig. S6, ESI $\dagger$ ), which indicates that electron transport is fast. Impedance spectra (Fig. S7, ESI + ) show the absence of the line feature at high frequencies and it can be fit using a 2CPE equivalent circuit (Fig. S8, ESI $\dagger$ ). These results are consistent with rapid electron transport due to coupling of $\operatorname{MoS}_{x}$ with Vulcan ${ }^{\mathbb{R}}$. The finding further validates our model and interpretation of impedance data.

In summary, we have developed a method based on electrochemical impedance spectroscopy to identify a slow electron transport process in HER catalysed by molybdenum sulphides. This method shall be useful for the study of many other electrocatalysts that are not good electronic conductors. Furthermore, we are able to accelerate electron transport in amorphous $\operatorname{MoS}_{x}$ catalysts via a new chemical synthesis, resulting in a more active and scalable catalyst. Finally, we provide new experimental evidence for significant electronic coupling between molybdenum sulphide catalysts and conducting carbon materials such as graphene, carbon nanotube and graphite.

This work was supported by an European Research Council starting grant (no. 257096) for LSCI and by the ERC Advanced Grant Agreement no. 247404 under the CE-Mesolight project funded by the European Community's Seventh FWP for LPI.

\section{Notes and references}

1 N. S. Lewis and D. G. Nocera, Proc. Natl. Acad. Sci. U. S. A., 2006, 103, 15729-15735.

2 T. F. Jaramillo, K. P. Jorgensen, J. Bonde, J. H. Nielsen, S. Horch and I. Chorkendorff, Science, 2007, 317, 100-102.

3 A. B. Laursen, S. Kegnaes, S. Dahl and I. Chorkendorff, Energy Environ. Sci., 2012, 5, 5577-5591.

4 J. Kibsgaard, Z. B. Chen, B. N. Reinecke and T. F. Jaramillo, Nat. Mater., 2012, 11, 963-969.

5 D. Merki and X. L. Hu, Energy Environ. Sci., 2011, 4, 3878-3888.

6 D. Merki, S. Fierro, H. Vrubel and X. L. Hu, Chem. Sci., 2011, 2, 1262-1267.

7 D. Merki, H. Vrubel, L. Rovelli, S. Fierro and X. L. Hu, Chem. Sci., 2012, 3, 2515-2525.

8 H. Vrubel, D. Merki and X. L. Hu, Energy Environ. Sci., 2012, 5, 6136-6144.

9 Y. G. Li, H. L. Wang, L. M. Xie, Y. Y. Liang, G. S. Hong and H. J. Dai, J. Am. Chem. Soc., 2011, 133, 7296-7299.

10 J. Kim, S. Byun, A. J. Smith, J. Yu and J. X. Huang, J. Phys. Chem. Lett., 2013, 4, 1227-1232.

11 X. J. Bian, J. Zhu, L. Liao, M. D. Scanlon, P. Y. Ge, C. Ji, H. H. Girault and B. H. Liu, Electrochem. Commun., 2012, 22, 128-132.

12 T. Y. Wang, L. Liu, Z. W. Zhu, P. Papakonstantinou, J. B. Hu, H. Y. Liu and M. X. Li, Energy Environ. Sci., 2013, 6, 625-633.

13 J. Bisquert, G. Garcia-Belmonte, F. Fabregat-Santiago, N. S. Ferriols, P. Bogdanoff and E. C. Pereira, J. Phys. Chem. B, 2000, 104, 2287-2298.

14 J. Bisquert, J. Phys. Chem. B, 2002, 106, 325-333.

15 F. Fabregat-Santiago, J. Bisquert, G. Garcia-Belmonte, G. Boschloo and A. Hagfeldt, Sol. Energy Mater. Sol. Cells, 2005, 87, 117-131.

16 J. O. M. Bockris and E. C. Potter, J. Electrochem. Soc., 1952, 99, 169-186. 